Article

\title{
Synthesis and Characterisation of ASA-PEEK Composites for Fused Filament Fabrication
}

\author{
Belén Palacios-Ibáñez ${ }^{1, *}$, José J. Relinque ${ }^{1, * \mathbb{D}}$, Daniel Moreno-Sánchez ${ }^{1} \mathbb{D}$, Alberto S. de León ${ }^{1}$ (D), \\ Francisco J. Delgado ${ }^{1} \mathbb{D}$, Ramón Escobar-Galindo ${ }^{2} \mathbb{D}$ and Sergio I. Molina ${ }^{1}$ (D)
}

1 Departamento de Ciencia de los Materiales e Ingeniería Metalúrgica y Química Inorgánica, IMEYMAT, Facultad de Ciencias, Campus Río San Pedro s/n, Universidad de Cádiz, 11510 Puerto Real (Cádiz), Spain; danielmoreno.sanchez@uca.es (D.M.-S.); alberto.sanzdeleon@uca.es (A.S.d.L.); fjavier.delgado@uca.es (F.J.D.); sergio.molina@uca.es (S.I.M.)

2 Departamento de Física Aplicada, Escuela Politécnica Superior, Universidad de Sevilla, C/Virgen de África 7 , 41011 Sevilla, Spain; rescobar1@us.es

* Correspondence: belen.palacios@uca.es (B.P.-I.); josejavier.relinque@uca.es (J.J.R.); Tel.: +34-956-01-2028 (B.P.-I. \& J.J.R.)

\section{check for}

Citation: Palacios-Ibáñez, B.

Relinque, J.J.; Moreno-Sánchez, D.; de León, A.S.; Delgado, F.J.; Escobar-Galindo, R.; Molina, S.I. Synthesis and Characterisation of ASA-PEEK Composites for Fused Filament Fabrication. Polymers 2022, 14, 496. https://doi.org/10.3390/ polym14030496

Academic Editor: Somen K. Bhudolia

Received: 12 December 2021 Accepted: 23 January 2022

Published: 26 January 2022

Publisher's Note: MDPI stays neutral with regard to jurisdictional claims in published maps and institutional affiliations.

Copyright: (C) 2022 by the authors. Licensee MDPI, Basel, Switzerland. This article is an open access article distributed under the terms and conditions of the Creative Commons Attribution (CC BY) license (https:// creativecommons.org/licenses/by/ $4.0 /)$.

\begin{abstract}
In this paper, a series of polymer composites made from acrylonitrile-styrene-acrylate (ASA) and poly (ether ether ketone) (PEEK) were manufactured. ASA acts as a polymer matrix while PEEK is loaded in the form of micro-particles that act as a reinforcing filler. The composites were compounded by single screw extrusion and then, different specimens were manufactured either via injection moulding (IM) or fused filament fabrication (FFF). Two different types of PEEK (commercial and reused) in different concentrations (3 and $6 \mathrm{wt} . \%$ ) were tested and their influence in the mechanical, structural, and thermal properties were studied. It was observed that reused PEEK enhanced the stiffness and tensile strength and thermal stability of the composites both, for injected and printed specimens. This evidences the suitability of these composites as potential candidates as novel materials with enhanced properties following an approach of circular economy.
\end{abstract}

Keywords: thermoplastic polymers; composite materials; fused filament fabrication; mechanical properties; thermal properties

\section{Introduction}

Circular economy has emerged in the last years as an alternative which allows to change the linear take-make-waste process [1,2]. While the conventional fabrication model implies transforming raw materials into final products which will be disposed at the end of their lifecycle, the circular economy approach considers that the generated waste can be reused as raw material in the same or another fabrication process. The products at the end of their lifecycle may be exploited instead of definitely losing their value, optimising the resources and making the manufacturing processes more sustainable.

Additive manufacturing (AM) processes involve a number of techniques where objects are manufactured upon a 3D computer aided designed model by the deposition of a material in a layer-by-layer approach [3]. The AM techniques are aligned with the circular economy approach, since they generate less waste than conventional subtractive techniques [4,5]. Moreover, they can easily fabricate parts with complex geometries and high added value in short-runs [6], saving energy and reducing operative costs [7-9].

AM technologies can be classified in seven different categories, depending on their physicochemical working principle [10]. Among these categories, material extrusion (ME) consists in the deposition of a molten material (typically thermoplastics or composites) through a heated nozzle at a temperature above its melting point. ME techniques include filament fused fabrication (FFF), which is the most widespread AM technology, since it is 
inexpensive and its fabrication conditions are milder compared to other AM technologies involving the manufacturing of metals or ceramics [11]. FFF allow the use of recycled plastics or other natural products as wood or cork, enabling more sustainable processes [11-15].

The most used materials for FFF are high molecular weight polylactic acid (PLA) and acrylonitrile-styrene-butadiene (ABS) terpolymer. These materials in their molten state present a proper viscoelastic behaviour (typically at $200-250^{\circ} \mathrm{C}$ ) that allows their processing via FFF [16,17]. Nevertheless, 3D-printed objects with PLA are relatively brittle and cannot be used above $60^{\circ} \mathrm{C}[18,19]$. ABS is preferred for most engineering applications, even though it has poor weather resistance due to the olefinic bonds present in the butadiene core, which is susceptible to UV degradation. This causes a decrease in the mechanical properties and yellowing of the material [20]. Acrylonitrile-styrene-acrylate (ASA) has emerged as an alternative that overcome these issues. The substitution of the butadiene rubber by an acrylate elastomer improves the weathering shown by ABS [21]. The mechanical performance of ASA can be further improved by combining it with other polymers or fibres [22].

On the other hand, poly (ether ether ketone) (PEEK), is a technical thermoplastic with high mechanical and thermal performance (Young's modulus $4000 \mathrm{MPa}$, tensile strength $100 \mathrm{MPa}$, glass transition temperature $153^{\circ} \mathrm{C}$, melting temperature $343^{\circ} \mathrm{C}$ ). This polymer is widely used in engineering applications that require a high mechanical performance that cannot be typically achieved with ASA or ABS. Moreover, PEEK also exhibits high chemical resistance [23,24]. Its major drawback lies in the higher processing temperatures required, compared to most of the thermoplastics and its high cost.

In this work, ASA-based composites containing PEEK suitable for FFF were prepared. PEEK was used as an additive, in the form of particles in a compromise to obtain materials with enhanced mechanical properties at an affordable cost. Due its high melting point, PEEK can be considered as a ceramic filler, so it is considered that a composite is obtained, instead of a blend of polymers. Two different PEEK grades were used as fillers: a commercial grade PEEK powder $(\mathrm{P})$ and a reused PEEK powder $(\mathrm{CP})$ generated from machining waste, following a circular economy approach. The composites were prepared by single screw extrusion and subsequently processed by injection moulding (IM) and FFF. Their mechanical properties were determined and the influence of the printing orientation and raster angles, as key parameters in the eventual tensile properties of the printed parts, were assessed as well. These results were correlated with structural characterisation by scanning electron microscopy (SEM) of the fracture surface of tested tensile specimens. Finally, the thermal behaviour of the composites was studied by termogravimetry analysis (TGA) and differential scanning calorimetry (DSC), pointing out the influence of PEEK in the thermal stability of the composites.

\section{Materials and Methods}

\subsection{Materials}

ASA (ASA LI 941 NC supplied by LG, Seoul, South Korea, and distributed by Biesterfeld Ibérica S.L., Barcelona, Spain) was used as the polymer matrix. Virgin PEEK (P) particles $\left(\mathrm{D}_{\mathrm{p}}<25 \mu \mathrm{m}\right)$ were supplied by Victrex, Lancashire, UK, and distributed by Policomplex S. L., Valencia, Spain (PEEK $150 \mathrm{XF}$ ). CoPEEK powder (CP) collected from machining waste with a wide granulometry ranging from micrometres to millimetres was supplied by Bieglo $\mathrm{GmbH}$, Hamburg, Germany. The CP particles were sieved using a vibratory sieve shaker (AS200, supplied by Retsch GmbH, Haan, Germany) and only the fraction 45-125 $\mu \mathrm{m}$ was used as a filler. All the materials were oven dried for at least $3 \mathrm{~h}$ at $80{ }^{\circ} \mathrm{C}$ and used without further modifications to prepare the composites.

\subsection{Synthesis of Composites}

The synthesis of the composites was carried out by melt extrusion using a benchtop single screw extruder (Noztek Pro Filament Extruder supplied by Noztek, Shoreham-by-Sea, $\mathrm{UK})$. ASA, CP, and P were introduced at different concentrations in the hopper, as presented 
in Table 1. The materials were processed at $260^{\circ} \mathrm{C}$, at a rotation speed of $60 \mathrm{rpm}$, and a filament of $1.75 \pm 0.5 \mathrm{~mm}$ diameter was obtained. To improve the dispersion of PEEK in the ASA matrix, the filaments obtained were air cooled, oven dried again for at least $3 \mathrm{~h}$ at $80^{\circ} \mathrm{C}$, chopped to pellets (3-5 mm in length), and reprocessed in a second extrusion cycle under the same conditions. Part of the filaments obtained were chopped again to obtain pellets suitable for injection moulding (IM).

Table 1. Prepared composites and synthesis conditions.

\begin{tabular}{cccc}
\hline Composite & Filler & Concentration (wt.\%) & Test Specimen Preparation \\
\hline Pristine ASA & - & - & IM, FFF \\
\hline ASA-3CP & CP & 3 & IM, FFF \\
ASA-6CP & & 6 & IM \\
\hline ASA-3P & \multirow{2}{*}{ P } & 3 & IM, FFF \\
ASA-6P & & 6 & IM \\
\hline
\end{tabular}

\subsection{Preparation of Samples}

Tensile testing specimens were manufactured by IM and FFF according to UNEEN ISO 527 standard (type 1BA specimens). Pellets of the different composites were injected using a Babyplast 6/10P (supplied by Cronoplast S.L., Abrera, Spain). The heat profile was $230 / 240 / 240{ }^{\circ} \mathrm{C}$ (plastification chamber/injector/die) and pellets were two times compressed at 70 and 50 bar, respectively, upon injection in the mould. On the other hand, 3D-printed tensile testing specimens were printed using a Raise 3D Pro2 printer (supplied by Raise 3D, Irvine, CA, USA). The .gcode file for the test specimens manufacturing was generated using the freeware IdeaMaker. Samples were manufactured modifying the orientation and raster angle of the infill to determine their influence in the mechanical properties of the materials with different building directions. Figure 1 summarises graphically the different orientations and raster angles tested. The printing speed was fixed to $25 \mathrm{~mm} / \mathrm{s}$ to ensure the proper printing of all the specimens, in particular V-90, which are rather slender. The rest of the printing conditions were left by default for ASA materials, according to IdeaMaker: $0.2 \mathrm{~mm}$ layer height, $100 \%$ infill, printing temperature $235^{\circ} \mathrm{C}$ and $100{ }^{\circ} \mathrm{C}$ bed temperature.

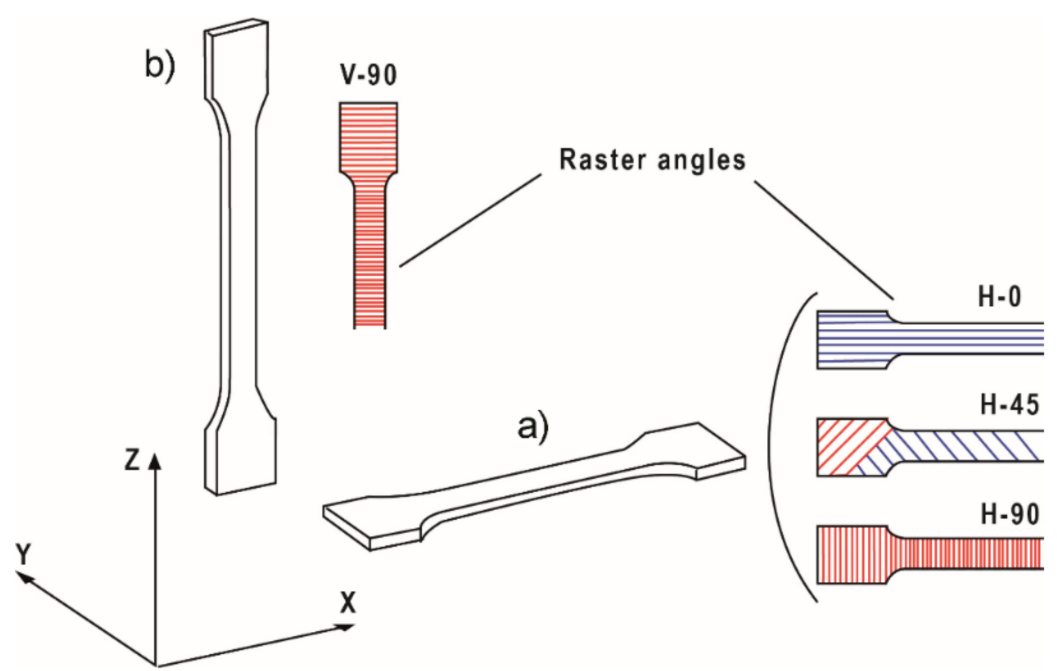

Figure 1. Orientations and raster angles of the different tensile test specimens. (a) Horizontal orientation, with raster angles parallel to the building axis, $\mathrm{X},\left(0^{\circ}, \mathrm{H}-0\right), \pm 45^{\circ}(\mathrm{H}-45)$, and perpendicular $\left(90^{\circ}, \mathrm{H}-90\right)$; (b) vertical orientation with the raster angle perpendicular to the building axis, Z, (V-90). 
ASA and 3 wt.\% PEEK composites were printed in horizontal and vertical orientation and the raster of the infill was varied from $0^{\circ}$ to $90^{\circ}$. The raster angle is that between the axial position of the specimen test and the infill. In the case of $\pm 45^{\circ}$ infill, the specimens are built alternating sequential layers at $45^{\circ}$ and $-45^{\circ}$ (see Figure 1 ).

\subsection{Characterisation Methods}

Structural and compositional characterisation of the composites was performed by SEM and Fourier-transformed infrared spectroscopy (FTIR). The fracture surface of the tensile testing specimens was observed by SEM. SEM images were taken using an Auriga CrossBeam microscope (supplied by Zeiss, Oberkochen, Germany) and a Scios 2 DualBeam microscope (supplied by ThermoFisher Scientific, Waltham, MA, USA). The microscopes were operated in SEM mode (secondary electrons images) under low voltage (3-15 kV). The samples were sputter-coated with Au using a high resolution sputter coater $208 \mathrm{HR}$ (supplied by Cressington, Watford, UK), prior to observation in SEM. FTIR analyses were carried out in a Bruker Alpha spectrometer (supplied by Bruker, Billerica, MA, USA) in the attenuated total reflectance (ATR) mode with a spectral resolution of $4 \mathrm{~cm}^{-1}$. Spectra were acquired from FFF printed monolayers of ASA, ASA-3P and ASA-3CP, and from P and CP powder.

The mechanical properties were evaluated by tensile testing of normalised specimens of the composites. For that purpose, a universal tester AGS-X (supplied by Shimadzu, Kyoto, Japan) was used. The specimens were all tested at $1 \mathrm{~mm} / \mathrm{min}$ and the results were the average of at least five experiments, in agreement with UNE-EN ISO 527.

Thermal characterisation of the composites was performed by TGA and DSC. Thermograms were obtained using a Q600 SDT analyser (supplied by TA Instruments-Waters LLC, New Castle, DE, USA) by heating the samples from $25^{\circ} \mathrm{C}$ to $900{ }^{\circ} \mathrm{C}$ at $10{ }^{\circ} \mathrm{C} / \mathrm{min}$ under inert $\mathrm{N}_{2}$ flow $(100 \mathrm{~mL} / \mathrm{min})$.

\section{Results and Discussion}

\subsection{Mechanical Properties of the Composites}

First, normalised specimens for tensile testing were manufactured by IM and tested in order to find out a trend in the mechanical behaviour of the composites. The results for the injected specimens are presented in the graphs depicted in Figure 2. The corresponding stress-strain curves have been included in Figure S1 as Supplementary Material.

According to the results, the stiffness (evaluated as Young's modulus, Figure 2a) and the strength (evaluated as yield strength, Figure $2 b$, and tensile strength, Figure $2 \mathrm{~d}$ ) improved for ASA-PEEK composites, compared to pure ASA. In particular, the Young's modulus increases up to $15 \%$ while the yield strength and the tensile strength increase $16 \%$ and 25\%, respectively. Previous reports show that ASA can improve the mechanical properties of polymer matrices such as SAN [20], PMMA [25], PVC [26], or PC [27] by blending, using high amounts of ASA. However, in this work, ASA is used as a matrix while PEEK (either CP or P) is acting as a filler (like a ceramic particle, since PEEK does not melt under the conditions used in this study). Hence, the composites consists of the dispersion of PEEK particles in an ASA matrix, rather than a blend of polymers. ASA-CP and ASA-P composites behave quite similar and exhibit comparable properties and trends when increasing the PEEK amount, even though they have different particle size. This supports that CP can be used instead of $\mathrm{P}$, evidencing that a PEEK as a waste can be used as feedstock instead of purchasing an expensive material as it is $\mathrm{P}$. 

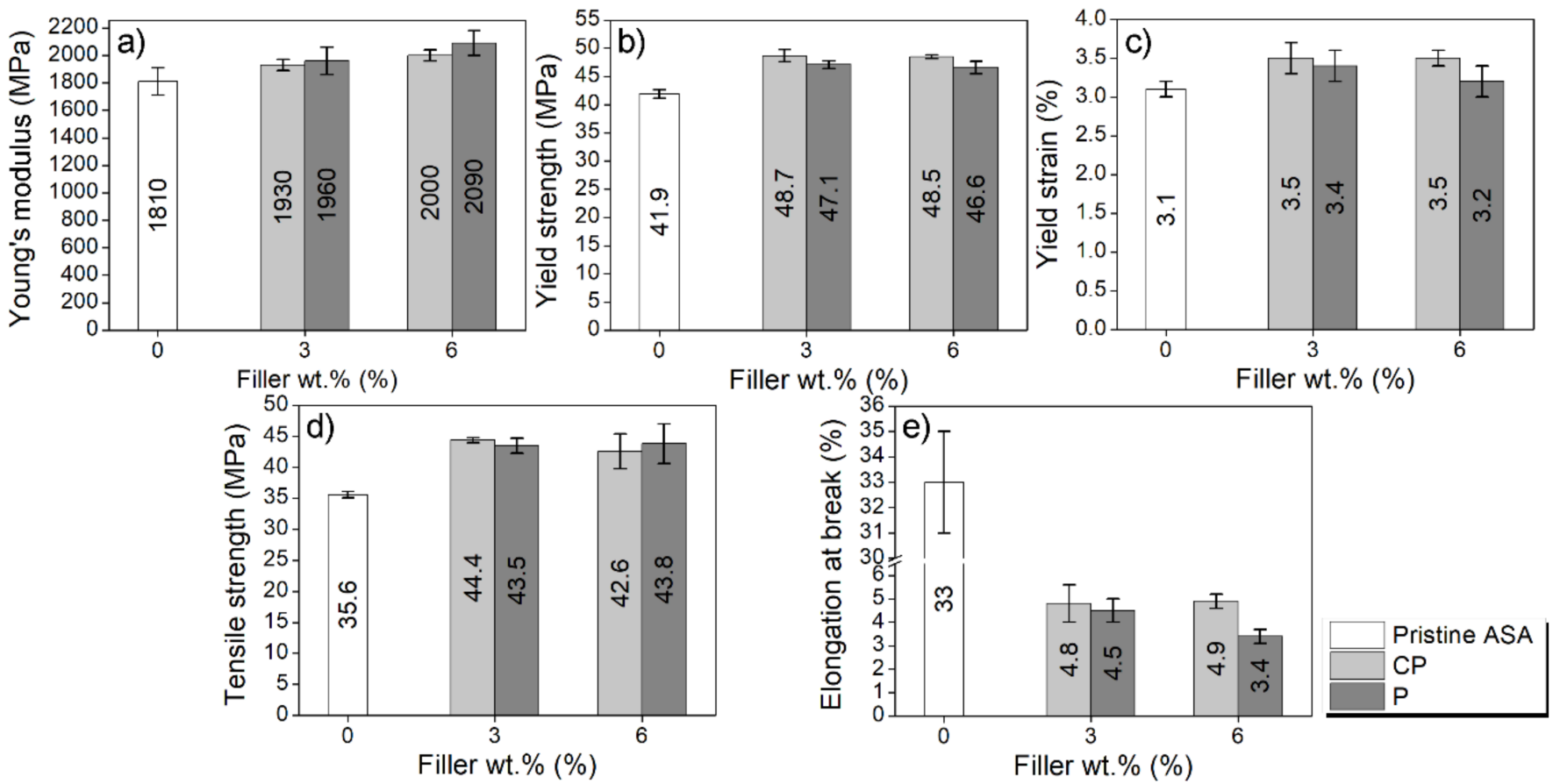

Figure 2. Mechanical properties of the injected pristine ASA (white bars), ASA-CP (light grey bars), and ASA-P (dark grey bars) with confidence intervals. (a) Young's modulus; (b) yield strength; (c) yield strain; (d) Tensile strength, and (e) elongation at break.

ASA-CP and ASA-P composites do not exhibit any improvement in mechanical properties when increasing the PEEK concentration. The presence of fillers in polymers implies a reduction in the free volume and, hence, limits the polymeric chain mobility. In principle, the mechanical properties are expected to increase when the filler content is higher [28]. However, this general trend is also affected by the dispersion and the compatibility (i.e., interface adhesion) of fillers with the polymeric matrix. In this case, in the absence of a proper blend between ASA and PEEK, an increase of PEEK content does not likely enhance the interface adhesion with ASA, together with an increase of agglomerations of PEEK [29]. As a result, the behaviour presented by the 3 and $6 \mathrm{wt} . \%$ PEEK composites is not significantly different.

Since an enhancement in the mechanical properties from 3 to $6 \mathrm{wt} . \%$ was not observed, only composites containing $3 \mathrm{wt} . \%$ PEEK (either P or CP) were printed via FFF. This permits to reduce the amount of PEEK used, while it is also expected to avoid clogging problems in the nozzle while printing [30].

Both fillers were tested to check out the behaviour of the composites when processed by FFF. The mechanical properties of ASA-3CP and ASA-3P composites printed by FFF in several orientations and raster angles (see Figure 1) are shown in Figure 3. The corresponding stress-strain curves have been included in Figure S2 as Supplementary Material.

The composites manufactured by FFF exhibit different properties when the raster angle is varied [31]. As observed in Figure 3, the best mechanical performance is expected in parts printed for $\mathrm{H}-0$ specimens. In this case, the tensile stress is held by each printed road rather than the bonds between roads which would support a minimum load. When the raster angle is varied, these bonds are forced to withstand part of the tensile stress as well as the roads. Therefore, for $\mathrm{H}-0$ samples, the fracture is dominated by the material failure whilst for $\mathrm{H}-45$ and $\mathrm{H}-90$ samples, delamination events happen through the bonds between roads, which eventually leads to material failure [32]. Similarly, the printing orientation plays a key role in the mechanical performance of FFF printed parts. Since the only possible raster angle in the vertical orientation is $90^{\circ}$ (V-90 samples), the roads 
are pulled perpendicularly during the tensile test, thus the main stress is exerted on the inter-layer bonds $[33,34]$.
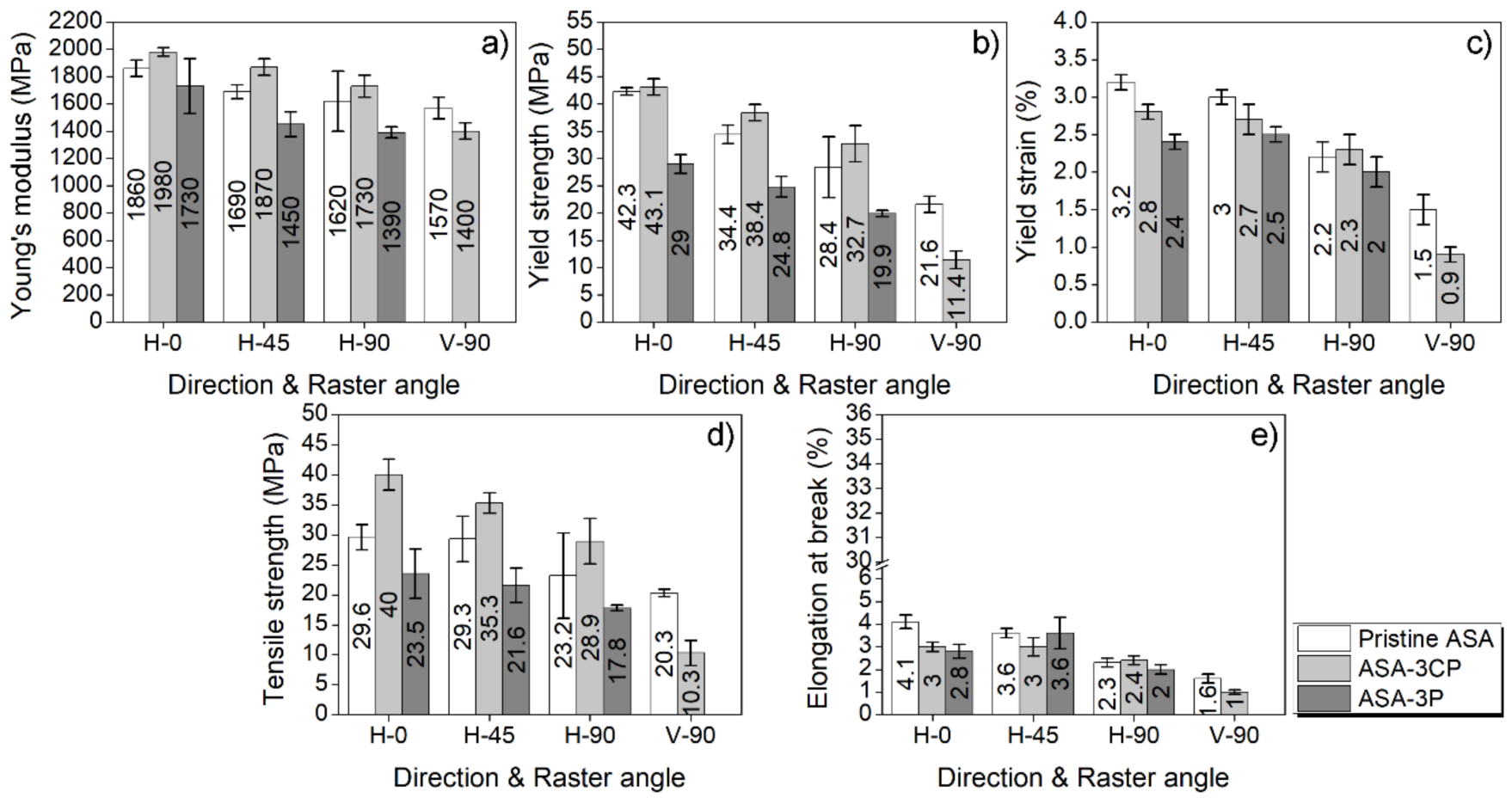

Figure 3. Mechanical properties of the FFF printed ASA (white bars), ASA-3CP (light grey bars), and ASA-3P (dark grey bars) with confidence intervals. (a) Young's modulus; (b) yield strength; (c) yield strain; (d) Tensile strength, and (e) elongation at break. The composites were printed in horizontal and vertical orientation, using raster angles of 0,45 and $90^{\circ}$ for the first orientation $(\mathrm{H}-0, \mathrm{H}-45$, and $\mathrm{H}-90$, respectively), and $90^{\circ}$ for the second one (V-90).

In this work, the composites are tested at different orientations and raster angles to identify the actual performance of 3D-printed objects under different building directions. The results presented in Figure 3 are coherent with the theoretical trend discussed and previous works found in the literature [35]. In general, the mechanical properties decrease when the raster angle is increased (i.e., the mechanical properties of $\mathrm{H}-0$ are higher than those of H-90) and the vertically printed parts exhibit the weakest mechanical performance, as expected. The stiffness (Figure 3a) and strength (Figure 3d) of ASA-CP increase up to $11 \%$ and $35 \%$, respectively, when compared to pristine ASA, while the elongation at break values decrease minimally (Figure 4e). These results are in agreement with previous reports using ABS or PLA-based composites [36]. However, vertically printed (V-90) ASA-PEEK composites are weaker than pristine ASA. In particular, V-90 ASA-P composites were extremely brittle. This did not allow to perform adequately the testing of its mechanical properties, since the test specimens broke when tightening them within the clamping jaws of the tester. Hence, these results are not represented in Figure 3. V-90 ASA-CP specimens were properly tested, even though they are more brittle than pristine ASA. This fact may be related to the different morphology of $\mathrm{CP}$ and $\mathrm{P}$, as it will be discussed below. 


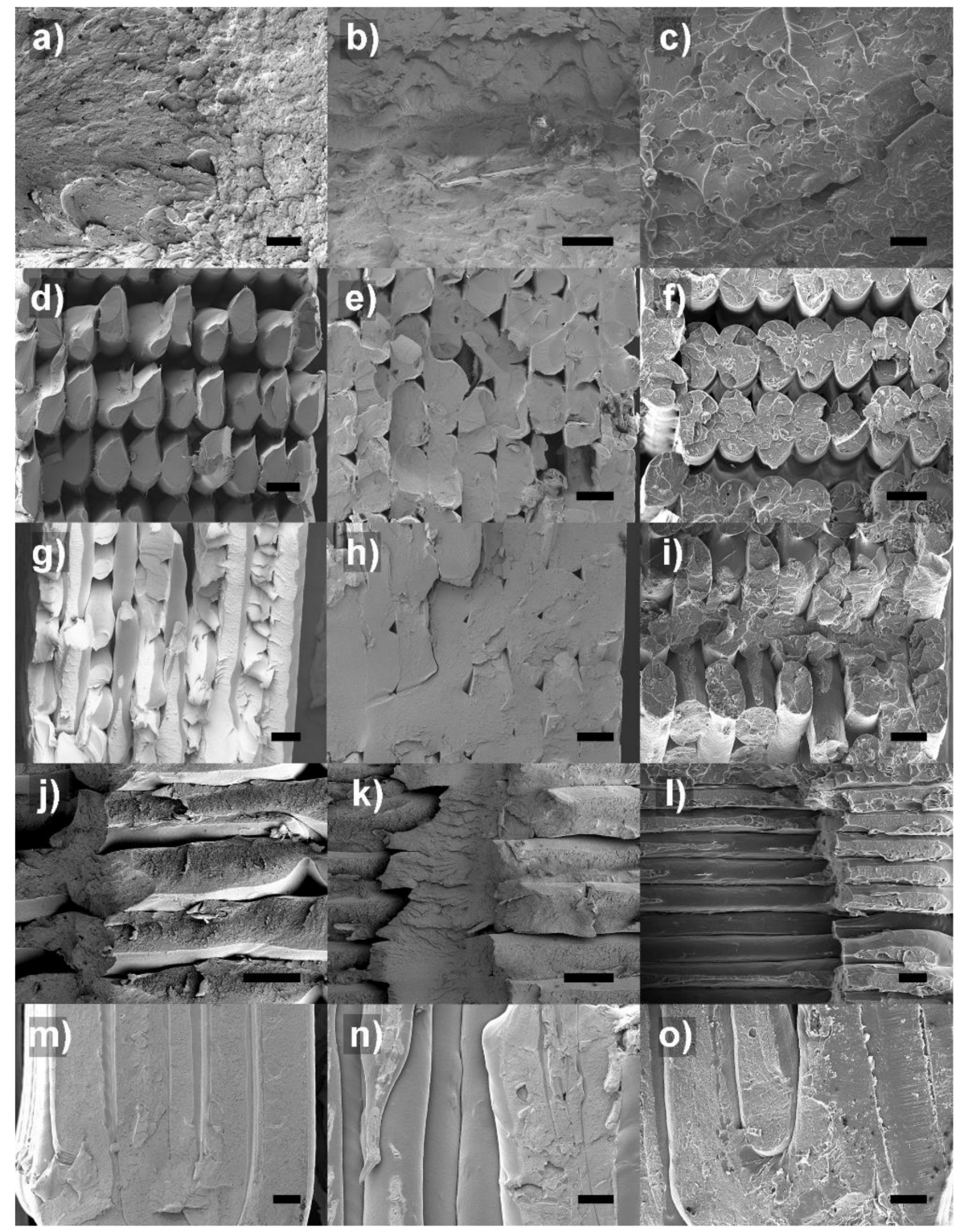

Figure 4. SEM images of the fracture surface of composites manufactured by (a-c) IM; (d-f) FFF-H0; (g-i) FFF, H45; (j-1) FFF, H-90, and (m-o) FFF, V-90. ASA ASA-3CP, and ASA-3P are presented in the left, middle, and right column, respectively. The scales bar stands for $200 \mu \mathrm{m}$ in all cases.

\subsection{Structural and Compositional Characterisation of the Composites}

The fracture surface of the composites was analyzed by SEM to obtain more information about the structural behavior of these materials, as depicted in Figure 4. Figure 4a shows the fracture surface of the pristine ASA manufactured by IM. It presents the characteristic aspect of a ductile fracture, exhibiting a rough surface caused by the plastic deformation of ASA before failure. On the contrary, ASA-3CP (Figure 4b) and ASA-3P (Figure 4c) composites prepared by IM present smoother surfaces. This can be correlated to the brittle behaviour previously observed for the composites. In the case of the FFF printed composites, all the raster angles can be easily noted. Since all of the specimens underwent a brittle fracture, the surfaces are more even than those observed by IM. SEM results evidence that, as stated before, the higher the raster angle, the more likely delamination can happen between roads of material [37]. The separation of roads is barely noticeable in $\mathrm{H}-0$ samples but it gradually increases for $\mathrm{H}-45$ and $\mathrm{H}-90$ specimens. In the case of $\mathrm{H}-90$, the fracture follows an axial path (instead of a straight crack, perpendicular to the tensile axis) and abrupt jumps can be observed along the fracture surface. 
ASA-3CP FFF printed composites, present some differences in the surface between the roads of the fracture surface (Figure $4 \mathrm{e}, \mathrm{h}, \mathrm{k}, \mathrm{n}$ ). These features, which can also be observed in the sample prepared by IM (Figure $4 \mathrm{~b}$ ), are not observed in pristine ASA, and present a characteristic roughness, so they are likely the $\mathrm{CP}$ particles. CP possess a higher particle size than $\mathrm{P}$, so it may have formed a binding structure between the roads and layers of ASA when printing, which would explain the improvement in mechanical properties observed either in FFF samples. This is neither observed for ASA-3P composites (Figure 4c,f,i,l,o), since the $\mathrm{P}$ particles have a significantly smaller average particle size. The fracture surface of ASA-3P exhibits a faceted texture in the shape of an irregular honeycomb structure. This is particularly clear for the IM sample (Figure 4c), while it gradually less perceptible in $\mathrm{H}-0, \mathrm{H}-45$, and $\mathrm{H}-90$ samples prepared by FFF (Figure $4 \mathrm{f}, \mathrm{i}, \mathrm{l}, \mathrm{o})$. This feature observed in the ASA-3P samples suggests that the filler could have acted as a nucleating agent for fractures, and the observed facets are formed after failure. This may be the reason behind the poor mechanical performance of these composites. On the contrary, in ASA-3CP composites, the $\mathrm{CP}$ particles seem to participate in the fracture mechanism as an actual reinforcing filler.

SEM images from the filaments were included in Figure S3 as Supplementary Material. Whilst some voids were observed around $\mathrm{CP}$ and $\mathrm{P}$ particles, since the diameter of the FFF extruder is lower than that of the injection nozzle, the formation of those imperfections within the deposited material during FFF printing is minimal when roads are deposited, as observed in Figure 4. This would explain the absence of porosity within the printed parts, beyond the gaps between printed roads.

Chemical analyses of the composites were carried out by ATR and the results are presented in Figure 5. Composites containing $\mathrm{CP}$ and $\mathrm{P}$ exhibit practically coincident spectra, indicating that the quality of the $\mathrm{CP}$ obtained as a by-product is similar than the one of pure PEEK powder (P). Then, the spectra of the composites exhibit signals corresponding both to ASA and PEEK. In these two cases, the spectra acquired also are rather similar. This indicates that the PEEK particles are homogeneously distributed within the ASA-3P and ASA-3CP composites. This effect can also be observed in the band at $1240 \mathrm{~cm}^{-1}$, corresponding to the $\mathrm{C}-\mathrm{O}$ stretching, that are shifted towards lower values, which could be caused by supramolecular interactions between ASA and PEEK.

a)

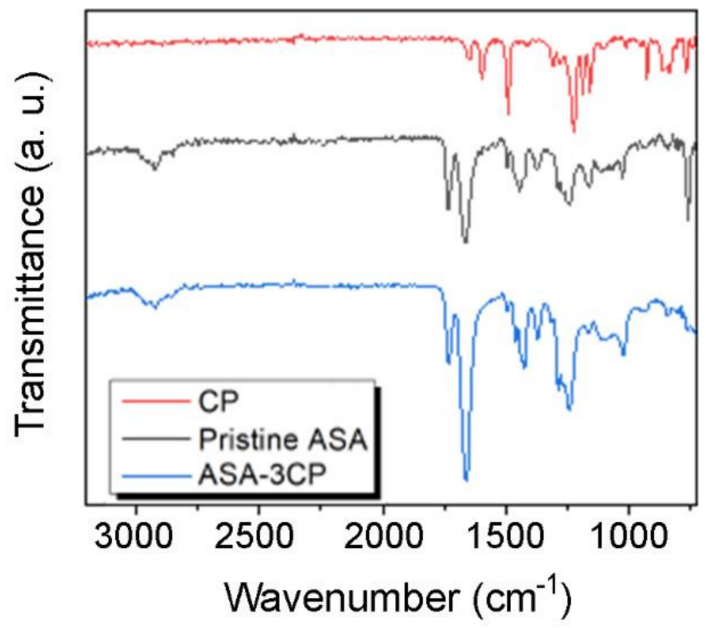

b)

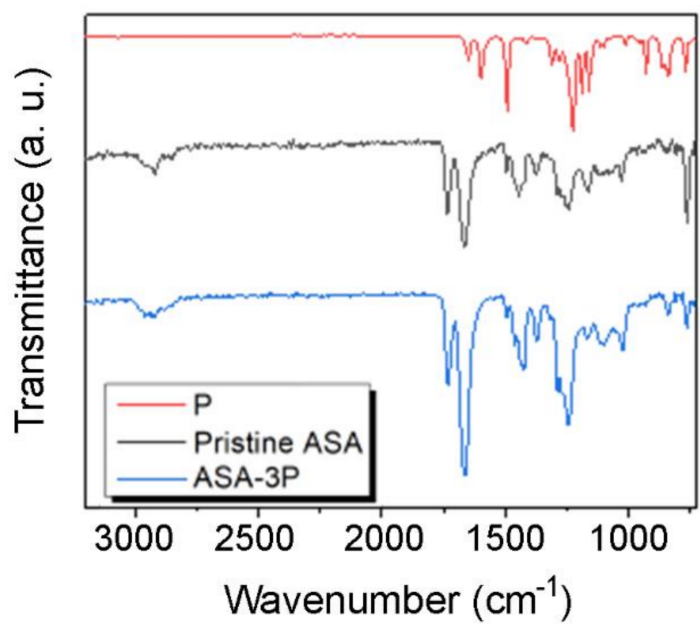

Figure 5. ATR spectra of (a) $\mathrm{CP}$, pristine ASA, and ASA-3CP, and (b) $\mathrm{P}$, pristine ASA, and ASA-3P.

\subsection{Thermal Characterisation of the Composites}

TGA and DSC analyses were carried out on pristine ASA, CP, P, and the composites containing 3 and $6 \mathrm{wt} . \%$ of either $\mathrm{CP}$ or P. The results are presented in Figure 6 together with the first derivative curves of TGA, i.e., derivative thermogravimetry (DTG). For pristine ASA, there is one single degradation step, with a maximum rate at $386{ }^{\circ} \mathrm{C}$, according to 
the DTG curve (Figure 6a). ASA fully degrades at $450{ }^{\circ} \mathrm{C}$. These results are in agreement with previous works found in the literature [38]. The thermograms corresponding to either $\mathrm{CP}$ and $\mathrm{P}$ show two decomposition stages (Figure 6e). According to the literature, the first one, ranging between $580-590{ }^{\circ} \mathrm{C}$ is caused by random chain scissions of ether and ketones, producing phenol and other aromatic compounds (benzene or dibenzofuran) as by-products. However, carbonyl bonds are more stable and able to resist these temperatures. The degradation of these bonds is produced in a second degradation peak at ca. $730{ }^{\circ} \mathrm{C}$. Above this temperature, a carbonaceous char, ranging from 46 to $50 \%$ of the original mass, is obtained as a residue [39].
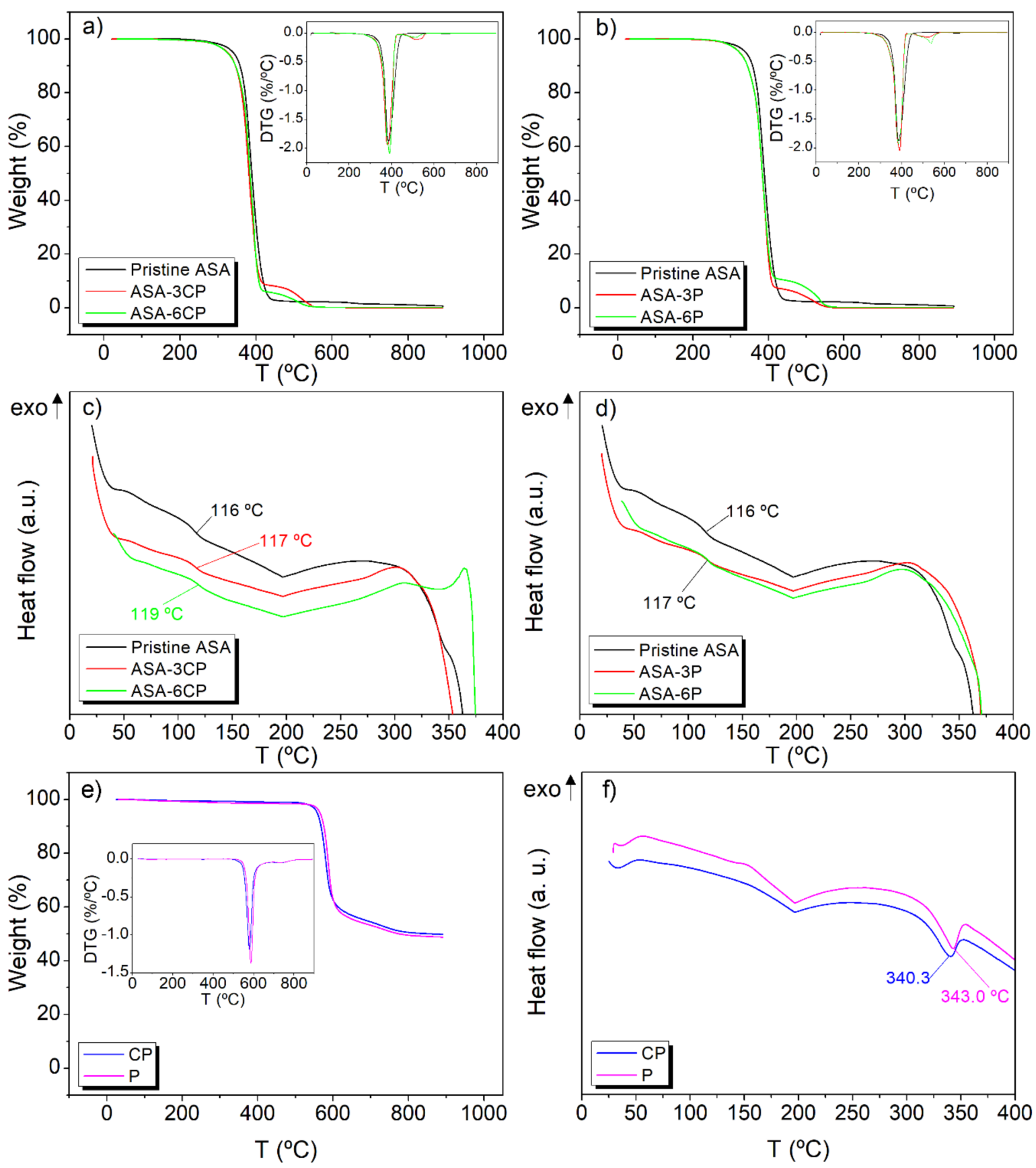

Figure 6. TGA thermograms of pristine ASA and (a) ASA-CP composites, and (b) ASA-P composites, (the corresponding DTG curves are included, respectively, in the insets); DSC curves of pristine ASA and (c) ASA-CP composites, and (d) ASA-P composites; (e) TGA thermograms of CP and P (with the corresponding DTG curves in the inset), and (f) DSC curves of CP and P. 
Regarding the DSC analysis, the literature describes for pristine ASA two glass transitions. The first one (not shown) at ca. $-45^{\circ} \mathrm{C}$, corresponding to the rubber part of the terpolymer and the second one corresponding to the poly (acrylonitrile-styrene) block at a temperature higher than $100{ }^{\circ} \mathrm{C}[18,31,33]$. As expected, the obtained curve for the pristine ASA observed in Figure 6 exhibits the second glass transition at $116^{\circ} \mathrm{C}$. No other thermal transitions are observed, due to the amorphous character of the terpolymer. DSC curves of either $\mathrm{CP}$ or $\mathrm{P}$ show their melting peak ranging $340^{\circ} \mathrm{C}$. Other authors report the presence of a glass transition and an exothermic crystallisation, due to its semi-crystalline behaviour, before observing the endothermic melting [40,41]. In this work these events are not perceptible, probably because these composites have undergone several heating and cooling cycles during the manufacturing, which may have induced a high crystallinity degree [42]. The ASA-PEEK composites present a similar degradation profile than pristine ASA, but including the second characteristic transition of PEEK. All the composites were fully degraded at the end of the experiment, i.e., the material was fully degraded at $400-500{ }^{\circ} \mathrm{C}$ (Figure 6a,b).

No clear trends were observed when increasing the filling rate and no influence of the filler in the thermal stability was observed. The DSC profiles of the composites and ASA were practically coincident, except for a slight increase in the glass transitions and a subtle increase in the temperature of decomposition (Figure $6 c, d$ ), so it can be concluded that the presence of $\mathrm{CP}$ or P slightly improves the thermal properties of ASA.

\section{Conclusions}

In this work, new ASA-PEEK suitable for IM and FFF was prepared. The composites retained the good processability of pristine ASA as well as its thermal stability, with improved stiffness and strength, even when low amounts of PEEK (i.e., 3 wt.\%) were used. This allows to have a new family of composite materials at an affordable cost, since PEEK is an expensive polymer material. Moreover, the use of CP shows the possibility of further reducing the cost of these materials, in the framework of circular economy. ASA-CP composite exhibited better properties than ASA-P, since a reinforcing structure was formed within the composite, likely due to the higher particle size, as evidenced by tensile testing and SEM analyses. CP exhibited a similar chemical behaviour than $\mathrm{P}$, indicating that it can replace virgin PEEK in these applications, which enables the development of new PEEK composite materials valid for FFF with a low environmental impact, expanding the current FFF portfolio of materials. The surface modification of the PEEK particles with compatibilising agents, as well as the use of PEEK fibres instead of particles are contemplated as future work, to achieve better mechanical properties.

Supplementary Materials: The following supporting information can be downloaded at: https: / / www.mdpi.com/article/10.3390/polym14030496/s1, Figure S1: Stress-strain curves of pristine ASA, ASA-CP, and ASA-P composites prepared by IM; Figure S2: Stress-strain curves of pristine ASA, ASA-3CP, and ASA-3P composites prepared by FFF in the following orientations and raster angles (a) H-0; (b) H-45; (c) H-90, and (d) V-90; Figure S3: SEM images of filaments used to FFF print (a) pristine ASA; (b) ASA-3CP, and (c) ASA-3P, showing some porosity within the filaments of ASA-3CP and ASA-3P.

Author Contributions: Conceptualisation, B.P.-I., J.J.R. and S.I.M.; Data curation, B.P.-I., J.J.R. and A.S.d.L.; Formal analysis, B.P.-I., J.J.R. and A.S.d.L.; Investigation, B.P.-I., J.J.R., A.S.d.L. and F.J.D.; Methodology, B.P.-I. and J.J.R.; Project administration, R.E.-G. and S.I.M.; Resources, R.E.-G. and S.I.M.; Supervision, R. Escobar-Galindo and S.I.M.; Writing-original draft, B.P.-I., J.J.R. and A.S.d.L.; Writing-review \& editing, J.J.R., D.M.-S., A.S.d.L. and S.I.M. All authors have read and agreed to the published version of the manuscript. 
Funding: This work was funded by the Junta de Andalucía 2014-2020 ERDF Operational Programme, the Department of Economy, Knowledge, Business and University of the Regional Government of Andalusia (sol-201800103710-tra, FEDER-UCA 3DMATFUN project), and Junta de Andalucía (Research group INNANOMAT, ref. TEP-946). Co-funding from UE and Navantia is also acknowledged. A.S. de León also acknowledges Ministry of Science, Innovation and Universities for his Juan de la Cierva Incorporación postdoctoral fellowship (IJC2019-041128-I). B. Palacios-Ibáñez also acknowledges Universidad de Cádiz and Grupo Fernández Jove for her industrial thesis predoctoral fellowship (TDI-5-19). SEM measurements were carried out at the DME-SC-ICyT-ELECMI-UCA.

Institutional Review Board Statement: Not applicable.

Informed Consent Statement: Not applicable.

Data Availability Statement: Not applicable.

Conflicts of Interest: The authors declare no conflict of interest. The funders had no role in the design of the study; in the collection, analyses, or interpretation of data; in the writing of the manuscript, or in the decision to publish the results.

\section{References}

1. Despeisse, M.; Baumers, M.; Brown, P.; Charnley, F.; Ford, S.J.; Garmulewicz, A.; Knowles, S.; Minshall, T.H.W.; Mortara, L.; Reed-Tsochas, F.P.; et al. Unlocking value for a circular economy through 3D printing: A research agenda. Technol. Forecast. Soc. Chang. 2017, 115, 75-84. [CrossRef]

2. Collias, D.I.; James, M.I.; Layman, J.M. Introduction-Circular Economy of Polymers and Recycling Technologies. In Circular Economy of Polymers: Topics in Recycling Technologies; ACS Symposium Series; American Chemical Society: Washington, DC, USA, 2021; Volume 1391, p. 1, ISBN 9780841298163.

3. Gibson, I.; Rosen, D.W.; Stucker, B. Additive Manufacturing Technologies: 3D Printing, Rapid Prototyping, and Direct Digital Manufacturing, 2nd ed.; Springer: Berlin/Heidelberg, Germany, 2015; ISBN 9781493921126.

4. Gordelier, T.J.; Thies, P.R.; Turner, L.; Johanning, L. Optimising the FDM additive manufacturing process to achieve maximum tensile strength: A state-of-the-art review. Rapid Prototyp. J. 2019, 25, 953-971. [CrossRef]

5. Rajaguru, K.; Karthikeyan, T.; Vijayan, V. Additive manufacturing-State of art. Mater. Today Proc. 2020, 21, 628-633. [CrossRef]

6. Tofail, S.A.M.; Koumoulos, E.P.; Bandyopadhyay, A.; Bose, S.; O’Donoghue, L.; Charitidis, C. Additive manufacturing: Scientific and technological challenges, market uptake and opportunities. Mater. Today 2018, 21, 22-37. [CrossRef]

7. Ullah, A.M.M.S.; Hashimoto, H.; Kubo, A.; Tamaki, J. Sustainability analysis of rapid prototyping: Material/resource and process perspectives. Int. J. Sustain. Manuf. 2015, 3, 20-36. [CrossRef]

8. $\quad$ Lin, K.-F.; He, S.; Song, Y.; Wang, C.-M.; Gao, Y.; Li, J.-Q.; Tang, P.; Wang, Z.; Bi, L.; Pei, G.-X. Low-Temperature Additive Manufacturing of Biomimic Three-Dimensional Hydroxyapatite/Collagen Scaffolds for Bone Regeneration. ACS Appl. Mater. Interfaces 2016, 8, 6905-6916. [CrossRef] [PubMed]

9. Sauerwein, M.; Doubrovski, E.; Balkenende, R.; Bakker, C. Exploring the potential of additive manufacturing for product design in a circular economy. J. Clean. Prod. 2019, 226, 1138-1149. [CrossRef]

10. Guo, N.; Leu, M.C. Additive manufacturing: Technology, applications and research needs. Front. Mech. Eng. 2013, 8, 215-243. [CrossRef]

11. Lee, J.Y.; An, J.; Chua, C.K. Fundamentals and applications of 3D printing for novel materials. Appl. Mater. Today 2017, 7, 120-133. [CrossRef]

12. Kreiger, M.A.; Mulder, M.L.; Glover, A.G.; Pearce, J.M. Life cycle analysis of distributed recycling of post-consumer high density polyethylene for 3-D printing filament. J. Clean. Prod. 2014, 70, 90-96. [CrossRef]

13. Vidakis, N.; Petousis, M.; Tzounis, L.; Maniadi, A.; Velidakis, E.; Mountakis, N.; Kechagias, J.D. Sustainable Additive Manufacturing: Mechanical Response of Polyamide 12 over Multiple Recycling Processes. Materials 2021, 14, 466. [CrossRef]

14. Pop, M.A.; Croitoru, C.; Bedo, T.; Geamăn, V.; Radomir, I.; Zaharia, S.M.; Chicoş, L.A. Influence of internal innovative architecture on the mechanical properties of 3D polymer printed parts. Polymers 2020, 12, 1129. [CrossRef] [PubMed]

15. Yao, J.; Odelius, K.; Hakkarainen, M. Microwave Hydrophobized Lignin with Antioxidant Activity for Fused Filament Fabrication. ACS Appl. Polym. Mater. 2021, 3, 3538-3548. [CrossRef]

16. Bourell, D.; Kruth, J.P.; Leu, M.; Levy, G.; Rosen, D.; Beese, A.M.; Clare, A. Materials for additive manufacturing. CIRP Ann.-Manuf. Technol. 2017, 66, 659-681. [CrossRef]

17. Popescu, D.; Zapciu, A.; Amza, C.; Baciu, F.; Marinescu, R. FDM process parameters influence over the mechanical properties of polymer specimens: A review. Polym. Test. 2018, 69, 157-166. [CrossRef]

18. Yu, L.; Dean, K.; Li, L. Polymer blends and composites from renewable resources. Prog. Polym. Sci. 2006, 31, 576-602. [CrossRef]

19. Relinque, J.; de León, A.; Hernández-Saz, J.; García-Romero, M.; Navas-Martos, F.; Morales-Cid, G.; Molina, S. Development of Surface-Coated Polylactic Acid/Polyhydroxyalkanoate (PLA/PHA) Nanocomposites. Polymers 2019, 11, 400. [CrossRef]

20. Zhang, W.; Chen, S.; Zhang, J. Influence of blend composition on mechanical properties of ASA/SAN binary blends. J. Thermoplast. Compos. Mater. 2013, 26, 322-335. [CrossRef] 
21. Guessasma, S.; Belhabib, S.; Nouri, H. Microstructure, Thermal and Mechanical Behavior of 3D Printed Acrylonitrile Styrene Acrylate. Macromol. Mater. Eng. 2019, 304, 1800793. [CrossRef]

22. Song, J.; Liu, X.; Zhang, Y.; Huang, B.; Yang, W. Carbon-fiber-reinforced acrylonitrile-styrene-acrylate composites: Mechanical and rheological properties and electrical resistivity. J. Appl. Polym. Sci. 2016, 133, 2-7. [CrossRef]

23. Zhao, Y.; Zhao, K.; Li, Y.; Chen, F. Mechanical characterization of biocompatible PEEK by FDM. J. Manuf. Process. 2020, 56, $28-42$. [CrossRef]

24. Dua, R.; Rashad, Z.; Spears, J.; Dunn, G.; Maxwell, M. Applications of 3d-printed peek via fused filament fabrication: A systematic review. Polymers 2021, 13, 4046. [CrossRef] [PubMed]

25. Mao, Z.; Zhang, X.; Jiang, G.; Zhang, J. Fabricating sea-island structure and co-continuous structure in PMMA/ASA and PMMA/CPE blends: Correlation between impact property and phase morphology. Polym. Test. 2019, 73, 21-30. [CrossRef]

26. Rimdusit, S.; Wongmanit, P.; Damrongsakkul, S.; Saramas, D.; Jubsilp, C.; Dueramae, I. Characterizations of poly(vinyl chloride)/acrylonitrile styrene acrylate blends for outdoor applications. Eng. J. 2014, 18, 105-118. [CrossRef]

27. Han, Y.; Liu, J.; He, X.J.; Zhou, C. Morphology and properties of ASA/ PC blends. Adv. Mater. Res. 2012, 450-451, 1467-1470. [CrossRef]

28. Salom, C.; Prolongo, M.G.; Toribio, A.; Martínez-Martínez, A.J.; de Cárcer, I.A.; Prolongo, S.G. Mechanical properties and adhesive behavior of epoxy-graphene nanocomposites. Int. J. Adhes. Adhes. 2017, 84, 119-125. [CrossRef]

29. Osman, A.F.; Mariatti, M. Properties of aluminum filled polypropylene composites. Polym. Polym. Compos. 2006, 14, 623-634. [CrossRef]

30. Lamm, M.E.; Wang, L.; Kishore, V.; Tekinalp, H.; Kunc, V.; Wang, J.; Gardner, D.J.; Ozcan, S. Material Extrusion Additive Manufacturing of Wood and Lignocellulosic Filled Composites. Polymers 2020, 12, 2115. [CrossRef] [PubMed]

31. Syrlybayev, D.; Zharylkassyn, B.; Seisekulova, A.; Akhmetov, M.; Perveen, A.; Talamona, D. Optimisation of strength properties of FDM printed parts-A critical review. Polymers 2021, 13, 1587. [CrossRef] [PubMed]

32. Rajpurohit, S.R.; Dave, H.K. Effect of process parameters on tensile strength of FDM printed PLA part. Rapid Prototyp. J. 2018, 24, 1317-1324. [CrossRef]

33. Chacón, J.M.; Caminero, M.A.; García-Plaza, E.; Núñez, P.J. Additive manufacturing of PLA structures using fused deposition modelling: Effect of process parameters on mechanical properties and their optimal selection. Mater. Des. 2017, 124, 143-157. [CrossRef]

34. de León, A.S.; Domínguez-Calvo, A.; Molina, S.I. Materials with enhanced adhesive properties based on acrylonitrile-butadienestyrene (ABS)/thermoplastic polyurethane (TPU) blends for fused filament fabrication (FFF). Mater. Des. 2019, 182, 108044. [CrossRef]

35. Singh, S.; Singh, G.; Prakash, C.; Ramakrishna, S. Current status and future directions of fused filament fabrication. J. Manuf. Process. 2020, 55, 288-306. [CrossRef]

36. Shanmugam, V.; Rajendran, D.J.J.; Babu, K.; Rajendran, S.; Veerasimman, A.; Marimuthu, U.; Singh, S.; Das, O.; Neisiany, R.E.; Hedenqvist, M.S.; et al. The mechanical testing and performance analysis of polymer-fibre composites prepared through the additive manufacturing. Polym. Test. 2021, 93, 106925. [CrossRef]

37. Arifvianto, B.; Wirawan, Y.B.; Salim, U.A.; Suyitno, S.; Mahardika, M. Effects of extruder temperatures and raster orientations on mechanical properties of the FFF-processed polylactic-acid (PLA) material. Rapid Prototyp. 2021, 27, 1761-1775. [CrossRef]

38. Zhang, Z.; Zhu, W.; Zhang, J.; Tian, T. Highly toughened poly (acrylonitrile-styrene-acrylic)/chlorinated polyethylene blends: Mechanical, rheological and thermal properties. Polym. Test. 2015, 44, 23-29. [CrossRef]

39. Vasconcelos, G.d.C.; Mazur, R.L.; Ribeiro, B.; Botelho, E.C.; Costa, M.L. Evaluation of decomposition kinetics of poly (ether-etherketone) by thermogravimetric analysis. Mater. Res. 2013, 17, 227-235. [CrossRef]

40. Saleem, A.; Frormann, L.; Iqbal, A. High Performance Thermoplastic Composites: Study on the Mechanical, Thermal, and Electrical Resistivity Properties of Carbon Fiber-Reinforced Polyetheretherketone and Polyethersulphone. Polym. Compos. 2007, 28, 785-796. [CrossRef]

41. Díez-Pascual, A.M.; Naffakh, M.; Gómez, M.A.; Marco, C.; Ellis, G.; Martínez, M.T.; Ansón, A.; González-Domínguez, J.M.; Martínez-Rubi, Y.; Simard, B. Development and characterization of PEEK/carbon nanotube composites. Carbon 2009, 47, 3079-3090. [CrossRef]

42. Sarasua, J.R.; Remiro, P.M.; Pouyet, J. The mechanical behaviour of PEEK short fibre composites. J. Mater. Sci. 1995, 30, 3501-3508. [CrossRef] 